\title{
High productivity of dry pea genotypes resistant to crenate broomrape in Mediterranean environments
}

\author{
Sara Fondevilla ${ }^{1}$ (D) Fernando Flores ${ }^{2} \cdot$ Amero A. Emeran $^{3} \cdot$ Mohamed Kharrat $^{4}$. \\ Diego Rubiales ${ }^{1}$
}

Accepted: 23 October 2017 /Published online: 9 November 2017

(C) INRA and Springer-Verlag France SAS 2017

\begin{abstract}
The cultivation of dry pea (Pisum sativum) is strongly hampered in Mediterranean and Middle Eastern farming systems by the parasitic weed Orobanche crenata. Resistant cultivars are not available to farmers, and only incomplete levels of resistance have been identified in landraces or wild relatives. Dry pea genotypes that combine the resistance of wild genotypes with good agronomic traits have been the focus of our breeding program. The objectives of this study were to evaluate the level and stability of resistance to $O$. crenata and the yield of these genotypes in different locations across the Mediterranean Basin and to identify the most useful environments in which to select for these traits. The responses to $O$. crenata and yield of pea genotypes were evaluated at five locations in Spain, Tunisia, and Egypt. Observed differences in both traits were due to the effect of genotype, environment, and environment $\times$ genotype interactions. A heritability-adjusted genotype plus genotype $\times$ environment interaction identified two mega-environments: the first, formed by the environments located in Egypt and the second, formed by the remaining environments. Breeding genotypes J26 and J26-2 showed good and stable yield and resistance responses to $O$. crenata in all environments. By contrast, $\mathrm{J} 3$ had a markedly different pattern depending on the mega-
\end{abstract}

Sara Fondevilla

sfondevilla@ias.csic.es

1 Institute for Sustainable Agriculture CSIC, Avda. Menéndez Pidal s/n, 14004 Córdoba, Spain

2 E.T.S.I. La Rábida, Huelva University, 21819 Palos de la Frontera, Spain

3 Faculty of Agriculture, Kafr El-Sheikh University, Kafr El-Sheikh 33516, Egypt

4 INRAT, Carthage University, Rue Hédi Karray, 2080 Ariana, Tunisia environment. It was one of the most resistant genotypes in the second mega-environment, but the most susceptible one in the Egyptian mega-environment. Both locations in Egypt were useful for selecting high yield and resistance to $O$. crenata, while, in the second mega-environment, Córdoba was the most useful in which to select for the traits. This study is the first to report advanced dry pea breeding genotypes that show resistance to $O$. crenata and high productivity in different environments. These genotypes will be highly useful in environmentally sustainable control of broomrape.

Keywords Pisum sativum - Genetic resistance - Orobanche crenata $\cdot$ Genotype $\times$ environment interactions

\section{Introduction}

Grain legumes are multifunctional annual crops with an extraordinary heritage and importance for agriculture and the environment; they improve soil fertility and minimize the use of inorganic nitrogen fertilizers, contributing to sustainable agriculture. Dry pea (Pisum sativum L.) is the most commonly and widely grown temperate grain legume in Europe and the second most commonly grown in the world (FAOSTAT 2014). While dry pea is a versatile and inexpensive source of protein used for animal feed and human consumption, its cultivation is strongly hampered in Mediterranean and Middle Eastern farming systems by the parasite crenate broomrape (Orobanche crenata Forsk.) (Rubiales et al. 2003), causing yield losses of up to $80 \%$ and complete loss of dry pea crops in severe cases (FernándezAparicio et al. 2016).

A series of agronomic and chemical measures are available to control broomrape (Joel et al. 2007; Rubiales et al. 2009(a)); however, often they are unfeasible or ineffective 
due to excessive cost and lack of ease of application. Cultivation of resistant varieties of dry pea would be the most economical and ecologically appropriate method to control $O$. crenata, and although little resistance is available within the cultivated dry pea, good sources of resistance have been reported in wild Pisum spp. (Rubiales et al. 2005). Our breeding program has used wild accessions of Pisum spp. as donors for incorporating resistance to $O$. crenata into cultivated types (Rubiales et al. 2009(b)) and as a result, several dry pea breeding genotypes with good levels of incomplete resistance have been selected (Fig. 1). However, little is known about the stability of the identified resistant phenotypes or the field performance of generated germplasm across the Mediterranean countries.

Resistance to $O$. crenata in dry pea is quantitative and polygenic (Fondevilla et al. 2010) and highly influenced by the environment. The effect of genotype $\times$ environment interactions attenuates the association between genotype and phenotype, making the selection of the most resistant genotypes more difficult. To counter this problem, genotype plus genotype-by-environment interaction (GGE) biplot analysis removes the statistical main effect of environment, and focuses on the genotype and genotype-by-environment interaction, that are the most relevant components in cultivar selection. GGE analysis has been successfully used in studies of the stability of faba bean resistance to $O$. crenata (Maalouf et al. 2011, Rubiales et al. 2014).

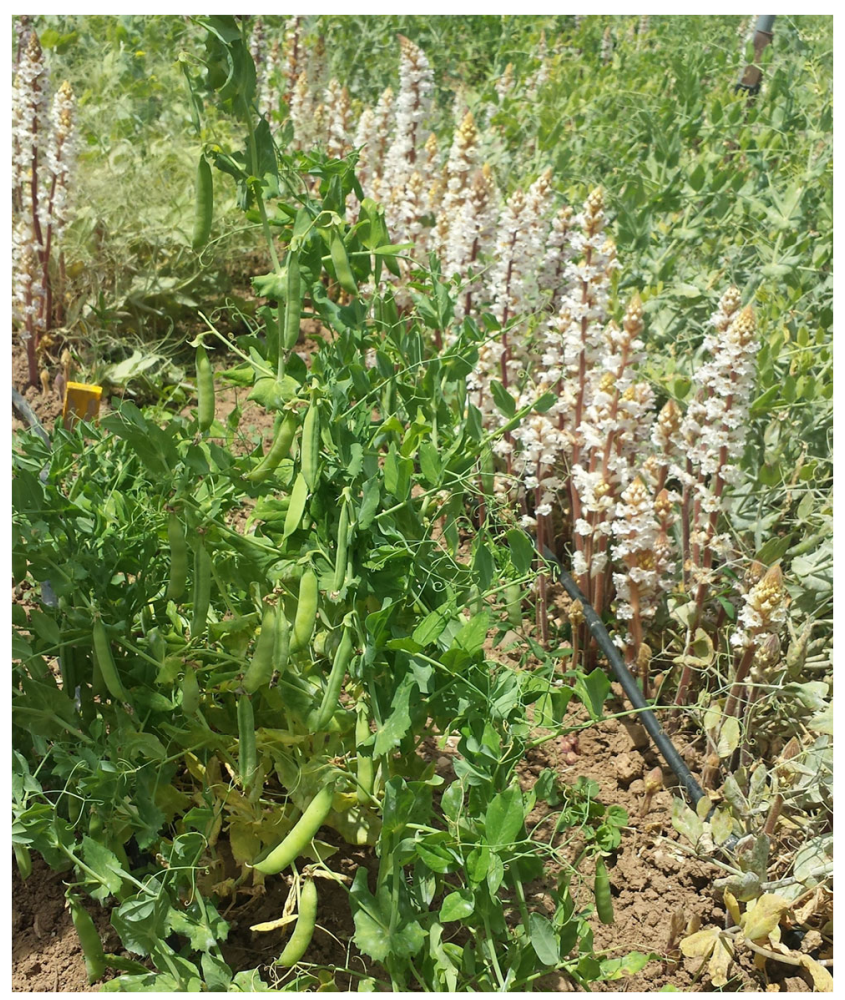

Fig. 1 Resistant breeding line J20 surrounded by susceptible pea cultivars
The objective of this study was to identify high-yielding dry pea genotypes from our breeding program (Rubiales et al. 2009(b)) that exhibited the best and most stable resistance to $O$. crenata and also to distinguish the most useful environments for selecting for these traits.

\section{Materials and methods}

\subsection{Plant materials}

The dry pea population comprised 16 dry pea genotypes obtained from our breeding program (Rubiales et al. 2009(b)) and cv. "Messire" as susceptible check (Table 1).

\subsection{Field experiments}

Dry pea genotypes were grown at five locations covering most of the Mediterranean Basin, from Egypt to Spain, and evaluated in at least one of the crop seasons 2006-2007, 20072008, and 2008-2009. The study sites were located in Córdoba (CORD), at the experimental farm "Tomejil" in Alcalá del Río (TOM) and Escacena del Campo (ESC) in Spain, in Kafr El-Sheikh (EGYP) in Egypt, and in Ariana (TUN) in Tunisia (Table 1). Since it was devoid of $O$. crenata, Tomejil was selected as control site to check for the yield potential of the genotypes in absence of the host parasite. All other study sites were selected because naturally high levels of $O$. crenata abundance had been observed in previous years. A randomized complete block design was used at all study sites, with three blocks at sites containing $O$. crenata and two blocks at the control site. In each block, 30 seeds of each dry pea line were sown in single plots at a density of around 70 seeds $\mathrm{m}^{-2}$. The dry pea cultivar Messire, which is highly susceptible to $O$. crenata under field conditions in Spain, was used as susceptible control at all study sites. Sowings were carried out between December and January. In accordance with local practice, study sites were not irrigated in Tunisia, Tomejil, or Escacena del Campo, whereas level basin flood irrigation was performed in Egypt at the beginning of December when the seeds were sown, in the middle of February and in the middle of March, with an application of $600 \mathrm{~m}^{3} \mathrm{ha}^{-1}$ on each occasion. Although irrigation of dry pea is not a local practice in Córdoba, plots were drip irrigated twice a week, during March, April, and May, applying about $165 \mathrm{~m}^{3} \mathrm{ha}^{-1}$ on each occasion, to ensure maximum $O$. crenata infection. At the end of the crop cycle, the level of infection in each plot was assessed by dividing the total number of dry pea plants by the total number of emerged $O$. crenata shoots in the plot. Similarly, yield was also scored on a plot basis by weighing the seeds produced per plot and estimating the corresponding amount of $\mathrm{kg} \mathrm{ha}^{-1}$. 


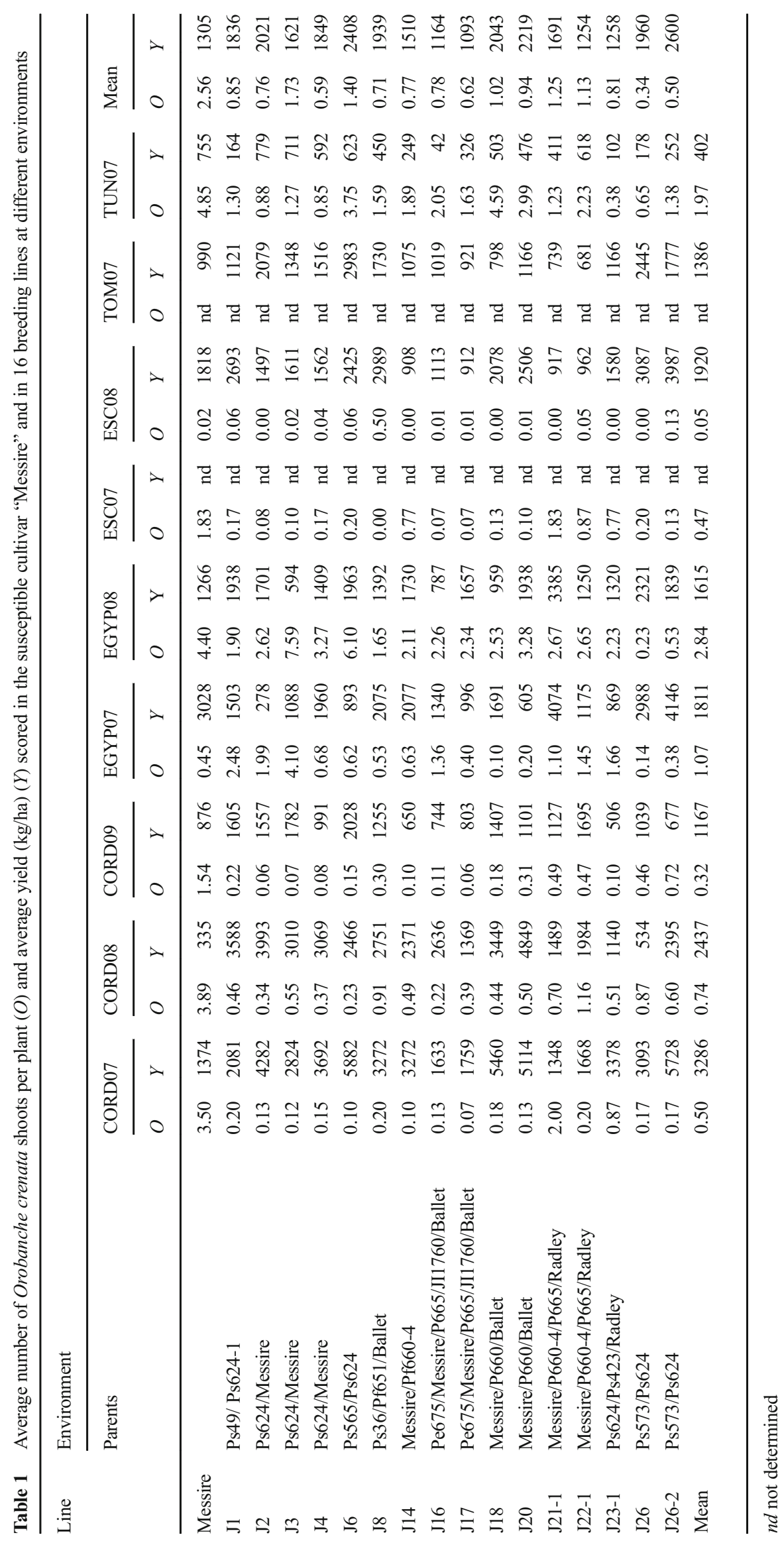




\subsection{Data analysis}

A two-way ANOVA for randomized complete block designs, with genotype and environments as main effects, to test for differences in rate of parasitism of $P$. sativum genotypes by $O$. crenata and yield of $P$. sativum genotypes was carried out using SAS 9.3 (SAS Institute Inc.). Prior to analysis, tests for normality and equality of variance were conducted for each dependent variable. Environments were defined as the combination of "cropping season" and "study site location" where each site in a given year was a separate environment. F ratios used to test effects for randomized complete block experiments combining location-year environments were determined according to McIntosh (1983).

Heritability-adjusted genotype plus genotype $\times$ environment interaction (HA-GGE) biplot was used for visual evaluation of the test environments and genotypes (Yan and Holland 2010; Flores et al. 2013; Sánchez-Martín et al. 2014), since it accounts for any heterogeneity among environments by giving weights to the test environments proportional to the root square of heritability $(\sqrt{ } H)$. The genotype $\times$ environment (GE) two-way tables were first centered with the respective means for the environments, multiplied by $\sqrt{ } H$ and then divided by the SD of the respective environment (Yan and Holland 2010). The HA-GGE biplot shows the first two principal components (PC1 and PC2) derived from the previous two-way table of each trait to singular value decomposition (Yan et al. 2000; Yan 2001). Singular value partitioning is achieved by providing a scaling factor, $f$, to obtain alternative genotypes and environment scores. We chose the most straightforward variant called symmetric scaling $(f=0.5)$, since it bears most of the properties associated with other scaling methods (Yan 2002). In a HA-GGE biplot, the projection of the vector of an environment onto the target environment axis abscissa $\left(\mathrm{TEA}_{\mathrm{a}}\right.$ ), as defined by Yan (2001), should approximate $r \sqrt{ } H$, where $r$ is the genetic correlation between the environments (Yan and Holland 2010) and is considered an overall, summary measure of the usefulness of an environment (Allen et al. 1978).

Data derived from the biplots were tested using nonparametric bootstrapping to construct $95 \%$ confidence intervals (CIs) on the basis of empirical distributions of the estimated parameters. Because singular value decomposition needs to be done on a balanced data set, we randomized (with replacement) either columns or rows, keeping the other fixed (Yang et al. 2009). This resampling process was repeated 1000 times to provide accurate estimates of CIs (Yang et al. 1996). Analyses were performed using SAS 9.3 (SAS Institute Inc.) program for graphing GGE biplots developed by Burgueño et al. (2003).

\section{Results and discussion}

Orobanche crenata is a devastating parasite affecting the growth and yield of dry pea, so the cultivation of resistant varieties could be an appropriate and effective method for its control. Using targeted, suitable methods for selecting the most resistant and productive genotypes of $P$. sativum is, therefore, crucial for controlling $O$. crenata. It is well known that environment influences growth and yield responses by $P$. sativum to $O$. crenata (Rubiales et al. 2003), so minimizing its effect is critical in resistance breeding programs. With this aim, we evaluated several breeding genotypes of $P$. sativum for resistance to $O$. crenata and yield in different environments.

As expected cv. Messire was highly susceptible to $O$. crenata, with a high number of emerged $O$. crenata shoots per plant in most environments. An exception was in EGYP07, where Messire hosted an unexpected low number of $O$. crenata shoots. The reasons for this anomaly are unclear. Similarly, Messire showed a low rate of $O$. crenata infection in ESC08, but here, infection in all the other genotypes in this environment was also very low, with no significant differences among them. In both cases, $O$. crenata infection was low in the seasons with a lower temperature. In addition, rainfall in ESC08 was low compared to ESC07. So, it is possible that lower temperature and rainfall could have hampered broomrape development.

By contrast, the breeding genotypes we tested showed different levels of incomplete resistance, with a lower average number of $O$. crenata shoots per plant than cv. Messire. Most of the breeding genotypes also showed a higher average yield than cv. Messire (Table 1). The analysis of variance showed that the observed differences in yield and $O$. crenata shoots per plant were the result of the effect of the genotype (indicating that the breeding lines tested have useful resistance genes), but also of the effect of the environment and the effect of genotype $\times$ environment interactions (Table 2 ). In the case of yield, $\mathrm{E}$ and $\mathrm{G} \times \mathrm{E}$ accounted for most of the observed variation (40 and $41 \%$, respectively). Differences due to $\mathrm{G}$ were also significant and explained around $12 \%$ of the variation. For the trait, $O$. crenata shoots per plant, $\mathrm{G}$ had a higher effect than E (explaining 18.8 and $5.8 \%$ of the variation, respectively) and there was a strong $\mathrm{G} \times \mathrm{E}$ interaction that accounted for $39 \%$ of the variation.

Given this high level of effect of the environment on yield and $O$. crenata shoots per plant, we applied HA-GGE biplots analysis to make an accurate evaluation of the genetic resistance and yield of the breeding genotypes. This kind of analysis had been proven to be an effective method for characterizing disease resistance and yield stability of breeding material in field trials (Villegas-Fernández et al. 2011; Rubiales et al. 2012; Flores et al. 2012, 2013; Sánchez-Martín et al. 2014). According to Yang et al. (2009), for a biplot to be useful, the 
Table 2 Analysis of variance showing the genotype $(\mathrm{G})$, environment $(\mathrm{E})$, and genotype $\times$ environment (GE) terms for the traits yield $(Y)$ and number of $O$. crenata shoots per plant $(O)$ scored in 17 pea lines at different environments

\begin{tabular}{llllll}
\hline Trait & Source of variation & Df & Sums of squares & $P$ value & Explained variation (\%) \\
\hline$Y$ & E & 7 & $261,798,883.0$ & $<.0001$ & 40 \\
& G & 16 & $76,106,558.5$ & $<.0001$ & 11.8 \\
& GE & 112 & $264,701,432.3$ & $<.0001$ & 41.3 \\
$O$ & E & 7 & 31.73497607 & 0.0040 & 5.8 \\
& G & 16 & 102.1377178 & $<.0001$ & 18.8 \\
& GE & 112 & 210.8001936 & $<.0001$ & 39 \\
\hline
\end{tabular}

Df means degrees of freedom; explained variation means percentage sums of squares respect from the total sums of squares first two principal components should account for approximately $60 \%$ of $\mathrm{G}+\mathrm{GE}$ variability and the combined effects of $\mathrm{G}+\mathrm{GE}$ should account for $>10 \%$ of $\mathrm{E}+\mathrm{G}+\mathrm{GE}$ variability. As shown in Fig. 2, these criteria were fulfilled for the traits of yield and $O$. crenata shoots per plant. Thus, for yield and $O$. crenata shoots per plant, the first two principal components explained 61 and $82 \%$ of total G + GE interaction, respectively, and $(\mathrm{G}+\mathrm{GE}) /(\mathrm{E}+\mathrm{G}+\mathrm{GE})$ yielded a value of 0.56 and 0.55 , respectively.

Yan et al. (2000) defined the term "mega-environment" as a meaningful subset of similar environments and showed that genotype selection is more accurate when conducted within such mega-environments. Therefore, we first searched for the presence of mega-environments in our experiment by using HA-GGE biplot analysis. For the trait of number of emerged $O$. crenata shoots per plant, the HA-GGE biplot clearly identified two different mega-environments, distinguishing the Egyptian study sites (ME1) from all remaining environments (ME2) (Fig. 1). The differences between number of emerged shoots in these two mega-environments were further confirmed by the lack of overlapping between the $95 \%$ bootstrap CIs corresponding to the environments belonging to ME1 and ME2 (data not shown).

Yields of P. sativum in EGYP07 and EGYP08 also differed clearly from those in the other environments, since the $95 \%$ bootstrap CIs for the vectors of these environments did not overlap with those of the other environments (Fig. 2). The analysis of yield in the environments not located in Egypt showed that the $95 \%$ CI corresponding to ESC08, TOM07, and CORD07 did not overlap with those of TUN07, CORD08, and CORD09. However, as these two groups have a location in common (Córdoba), we considered that they belong to the same mega-environment. Therefore, we conclude that the ME1 and ME2 mega-environments identified for yield and $O$. crenata resistance were the same.

$P$. sativum yield and resistance to $O$. crenata were negatively correlated in both mega-environments, highlighting the effect of $O$. crenata in dry pea productivity. However, this correlation was stronger in ME1, where the level of $O$. crenata infestation was higher $(r=-0.30 ; P=0.001)$ than in ME2 $(r=-0.24 ; P<0.001)$. It has been shown that low

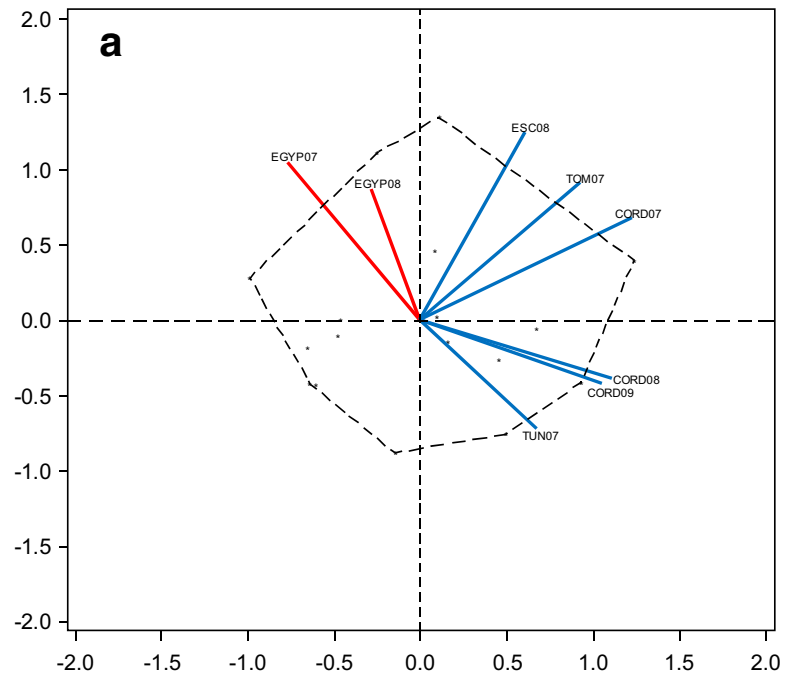

U

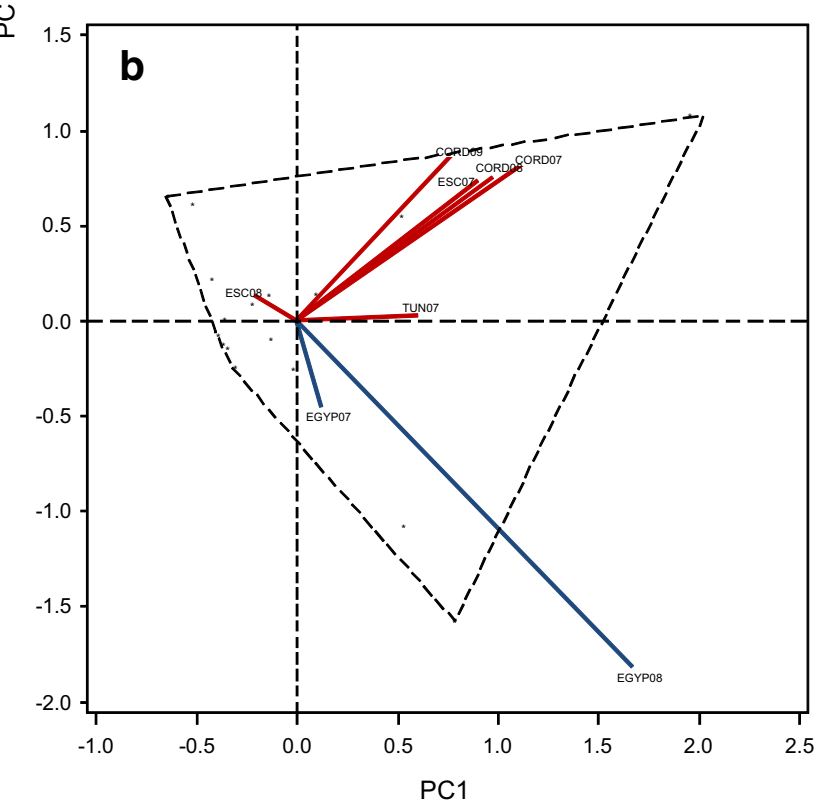

Fig. 2 Heritability-adjusted genotype plus genotype $\times$ environment interaction (HA-GGE) biplots for a yield and $\mathbf{b}$ number of $O$. crenata shoots/plant. Córdoba (CORD), Escacena del Campo (ESC), Tomejil (TOM), Ariana (TUN), Kafr El-Sheik (EGYP), 2007 (07), 2008 (08), 2009 (09). a PC1 $=34 \%, \mathrm{PC} 2=27 \%$, Sum $=61 \%(\mathrm{G}+\mathrm{GE}) /(\mathrm{E}+$ $\mathrm{G}+\mathrm{GE})=0.56 ; \mathbf{b} \mathrm{PC} 1=47 \%, \mathrm{PC} 2=35 \%, \mathrm{Sum}=82 \%(\mathrm{G}+\mathrm{GE}) /(\mathrm{E}+$ $\mathrm{G}+\mathrm{GE})=0.55$ 
temperature delays Orobanche spp. development (Pérez-deLuque et al. 2016) and we suggest that the higher temperatures that characterized ME1 could have promoted broomrape development.

Yan et al. (2007) stated that test environment evaluation and genotype selection become meaningful only when conducted within mega-environments, so we created separate

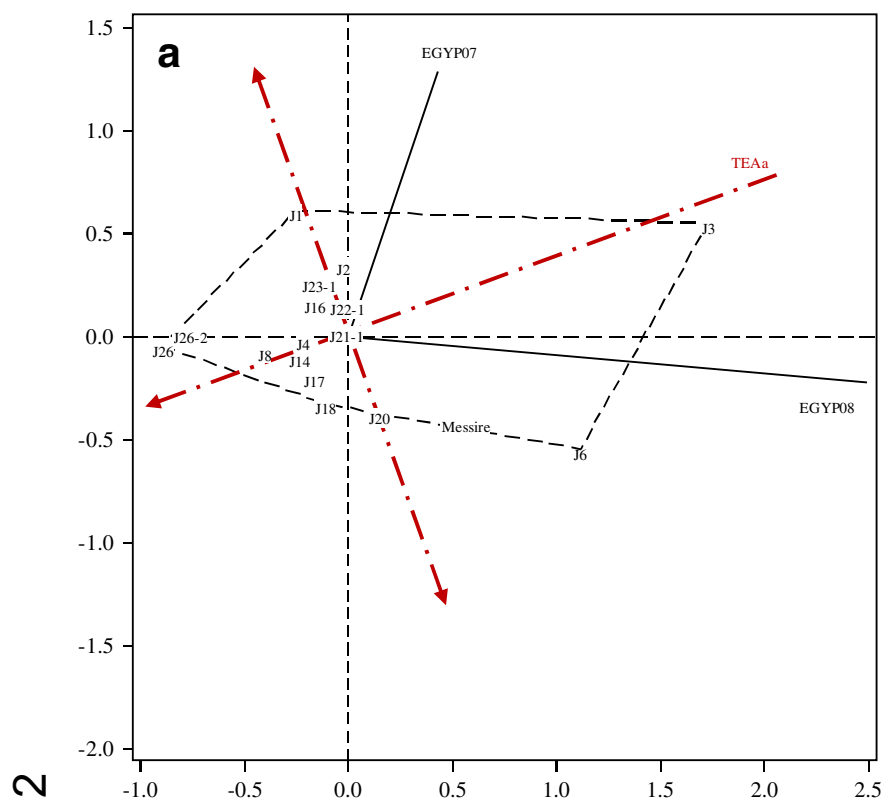

○

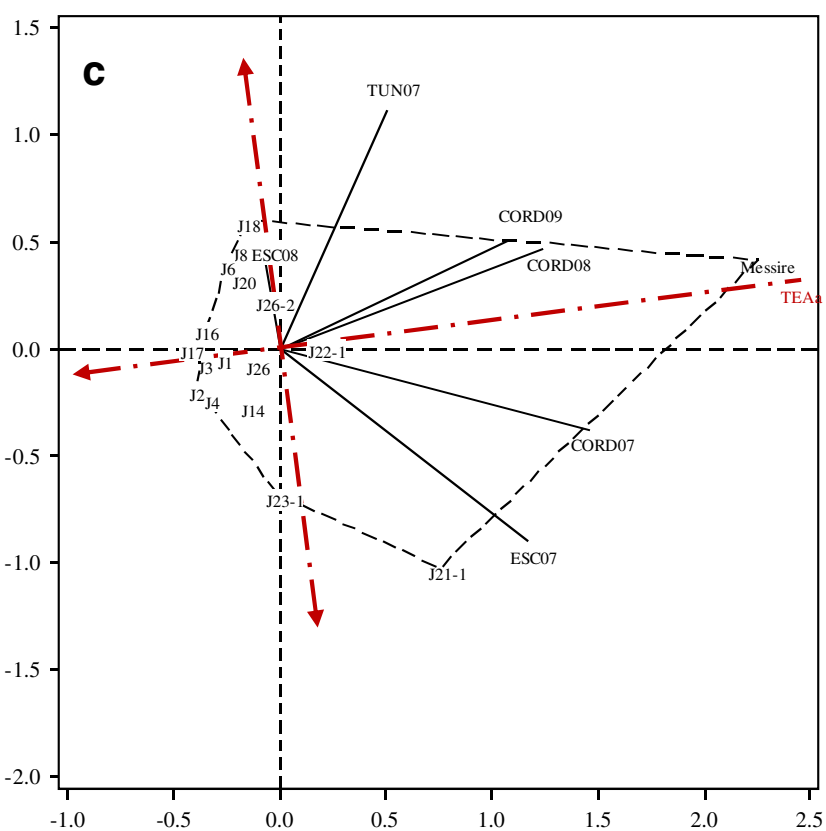

biplots for each mega-environment (Fig. 3). Using these specific mega-environment biplots, the average yield and number of $O$. crenata shoots per plant and their phenotypic stability were examined for the different genotypes. In HA-GGE biplots, the average of the genotypes is approximated by the projections of their markers onto the target environment axis abscissa $\left(\right.$ TEA $\left._{\mathrm{a}}\right)$ and the stability is measured by their
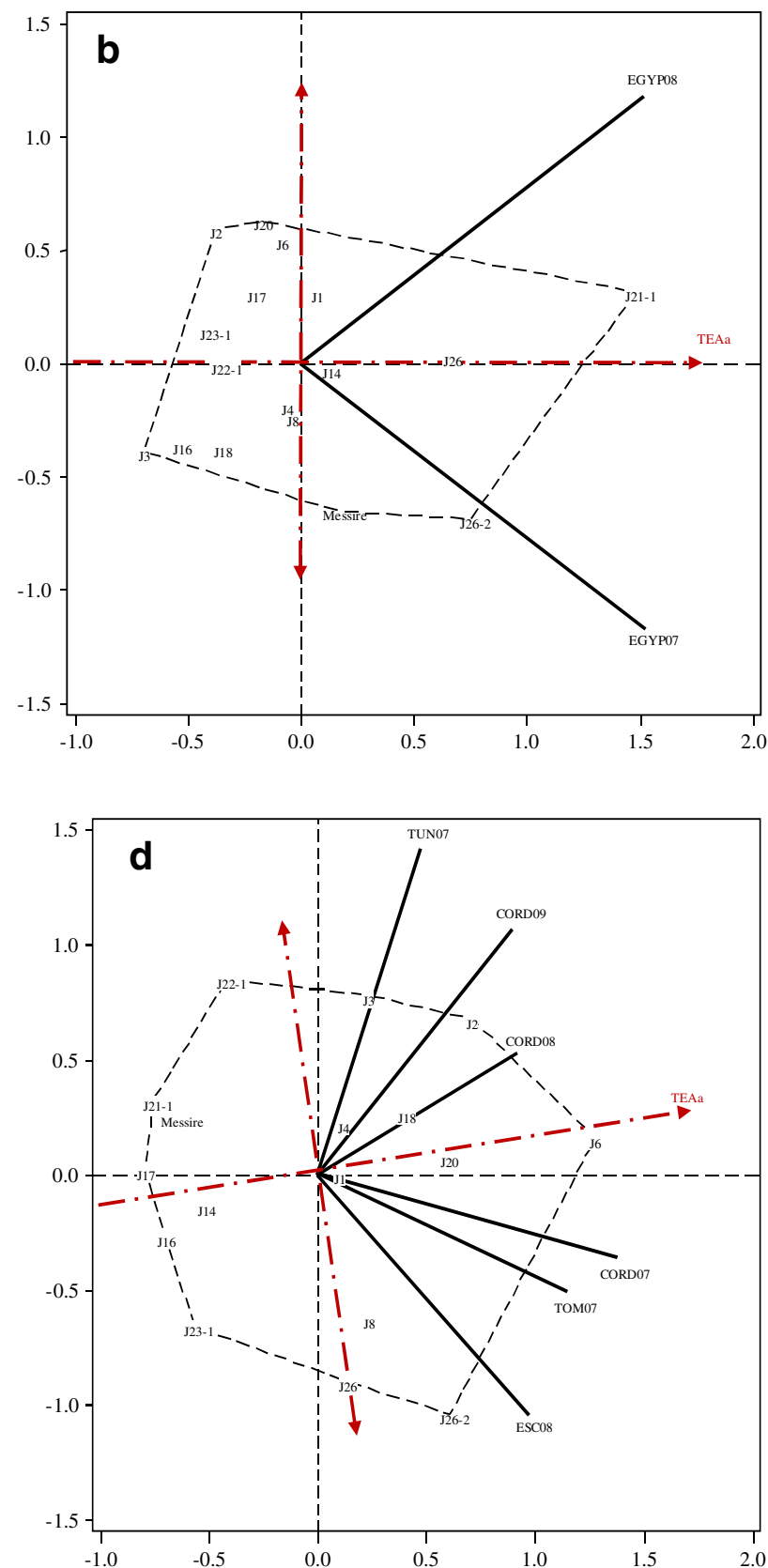

PC1

Fig. 3 HA-GGE biplots based in number of $O$. crenata shoots per plant (a and c) and yield (b and d), scored in 17 pea lines for the megaenvironment ME1 (a and b) or mega-environment ME2 (c and d). Córdoba (CORD), Escacena del Campo (ESC), Tomejil (TOM), Ariana (TUN), Kafr El-Sheik (EGYP), 2007 (07), 2008 (08), 2009 (09). a
$\mathrm{PC} 1=93 \%, \mathrm{PC} 2=7 \%$, Sum $=100 \%(\mathrm{G}+\mathrm{GE}) /(\mathrm{E}+\mathrm{G}+\mathrm{GE})=0.72 ;$ b $\mathrm{PC} 1=74 \%, \mathrm{PC} 2=26 \%$, Sum $=100 \%(\mathrm{G}+\mathrm{GE}) /(\mathrm{E}+\mathrm{G}+\mathrm{GE})=0.98$; c $\mathrm{PC} 1=72 \%, \mathrm{PC} 2=13 \%, \mathrm{Sum}=85 \%(\mathrm{G}+\mathrm{GE}) /(\mathrm{E}+\mathrm{G}+\mathrm{GE})=0.61 ; \mathbf{d}$ $\mathrm{PC} 1=40 \%, \mathrm{PC} 2=26 \%, \mathrm{Sum}=66 \%(\mathrm{G}+\mathrm{GE}) /(\mathrm{E}+\mathrm{G}+\mathrm{GE})=0.50$ 
projection to the TEA ordinate. The greater the absolute length of the projection of a genotype, the less stable it is. The biplots were also informative for identifying the most useful environments for selecting for the traits scored. In the biplots, the vector length of the environment is proportional to the square root of the heritability in the environment and, therefore, indicative of the discrimination power for identifying differences between the genotypes. The cosine of the angle between environment and $\mathrm{TEA}_{\mathrm{a}}$ is an estimate of their correlation that assesses the representativeness of the environment. Reproducibility between environments is evaluated by the cosine of the angles between these environments (Flores et al. 2013).

Both EGYP07 and EGYP08 were useful environments for selecting high yield, as they showed high levels of discrimination power, as indicated by the long length of the vectors. The most productive genotypes in the ME1 megaenvironment were J21-1, J26-2, and J26. Furthermore, J26 was located in the $\mathrm{TEA}_{\mathrm{a}}$ abscissa in the graph, highlighting its great phenotypic stability. The less productive genotype was J3 (Fig. 3).

EGYP08 was a more discriminative environment than EGYP07 for assessing the trait of number of $O$. crenata shoots per plant, as shown by the longer vector length. We found that the level of $O$. crenata infection was greater in EGYP08 and suggest this probably allowed for better discrimination between genotypes that had different levels of resistance. The most resistant genotypes in ME1 were J26, J26-2, and J8, and similarly for yield, J26 and J26-2 were very stable. The most susceptible genotype coincided with the genotype with the lowest yield in this mega-environment, J3 (Fig. 3).

Córdoba was the most useful environment in which to select for yield in mega-environment ME2, as characterized by the acute angles with TEA that were indicative of representativeness of the environment, and the long vectors that were indicative of its high level of discrimination capability. There were also acute angles between the vectors that corresponded to the different seasons, indicating that yields in this environment were very reproducible. Similarly, Córdoba was also the most useful environment in which to selecting for resistance to O. crenata (Fig. 3). The most productive genotypes in ME2 were J6, J2, J18, J20, J26, and J26-2, with J6 and J20 showing outstanding phenotypic stability across environments. By contrast, the less productive genotypes were J17, J21-1, and cv. Messire. Genotypes J2, J4, J17, J3, J16, and J1 were the most resistant genotypes in the ME2 mega-environment, and $\mathrm{J} 1, \mathrm{~J} 3$, and J26 showed the most phenotypic stability. As expected, the most susceptible line was cv. Messire (Fig. 3).

For breeding purposes, it is useful to identify sources of germplasm that confer effective resistance across many different environments, but genotypes that show outstanding environment-specific resistance could be also interesting for cultivar development for cultivation in this specific environment. The HA-GGE biplot analysis identified two such examples of dry pea genotype; J26 and J26-2 showed consistently high and stable levels of resistance and productivity in all environments, while the stability of these traits in J3 depends on the mega-environment in which they were grown. J3 was one of the most resistant genotypes in ME2, yet the most susceptible in ME1 and since yield was highly correlated with the number of $O$. crenata shoots per plant $(r=-0.66)$, it was more highly productive in ME2. Differential responses to $O$. crenata of genotypes grown in Kafr El-Sheikh compared to Córdoba have been also observed in other studies. For example, in a study evaluating a faba bean segregating population against $O$. crenata, a lack of correlation was observed between the field trials carried out in Córdoba and Kafr El-Sheikh and the genomic regions controlling resistance differed between the two environments. Furthermore, the susceptible check used in Córdoba showed a moderate resistance in Egypt (Gutiérrez et al. 2013). Although races have not been reported in $O$. crenata and genetic variability has principally been attributed to differences among individuals within populations, there have been reports of significant genetic differentiation among $O$. crenata populations from different countries (Román et al. 2002). Genetic differences between the $O$. crenata populations in megaenvironments ME1 and ME2 may exist that may have caused the contrasting trait responses we observed in $\mathrm{J} 3$. Alternatively, the differential responses in $\mathrm{J} 3$ may have been caused by the different methods of farming and environmental conditions in Córdoba and Kafr El-Sheikh, where growing conditions in Kafr El-Sheikh are characterized by shorter growing seasons and higher temperatures compared to Córdoba.

\section{Conclusions}

We found several breeding genotypes of $P$. sativum showing good levels of resistance to $O$. crenata and yield in different environments. Therefore, these genotypes are useful sources of germplasm for resistance. In addition, our study provided reliable criteria against which to select the best genotypes for yield and resistance to $O$. crenata that minimize the effects of genotype $\times$ environment interactions. The most stable genotypes across contrasting environments were J26 and J26-2 and the best environments in which to discriminate between genotypes for resistance and yield traits were Kafr El-Sheikh in Egypt and Córdoba in Spain.

Acknowledgements SF was funded by the Ramón and Cajal program from the Spanish Ministry of Economy and Competitiveness. This work was supported by the Spanish Ministry of Economy and Competitiveness (AGL2014-52871R) co-financed by FEDER. 


\section{References}

Allen FL, Comstock RE, Rasmusson DC (1978) Optimal environments for yield testing. Crop Sci 18:747-751

Burgueño J, Crossa J, Vargas M (2003) SAS programs for graphing GE and GGE Biplots. Biometrics and Statistics Unit CIMMYT, Mexico

FAOSTAT (2014) www.faostat.fao.org/faostat/en/\#data/QC (visited on July 2017)

Fernández-Aparicio M, Flores F, Rubiales D (2016) The effect of Orobanche crenata infection severity in faba bean, field pea and grass pea productivity. Front Plant Sci 7:1409. https://doi.org/10. 3389/fpls.2016.01409

Flores F, Hybl M, Knudsen JC, Marget P, Muel F, Nadal S, Narits L, Raffiot B, Sass O, Solis I, Winkle J, Stoddard FL, Rubiales D (2013) Adaptation of spring faba bean types across European climates. Field Crop Res 145:1-9. https://doi.org/10.1016/j.fcr.2013.01.022

Flores F, Nadal S, Solis I, Winkler J, Sass O, Stoddard FL, Link W, Raffiot B, Muel F, Rubiales D (2012) Faba bean adaptation to autumn sowing under European climates. Agron Sustain Dev 32:727734. https://doi.org/10.1007/s13593-012-0082-0

Fondevilla S, Fernández-Aparicio M, Satovic Z, Emeran AA, Torres AM, Rubiales D (2010) Identification of quantitative trait loci for specific mechanisms of resistance to Orobanche crenata in pea. Mol Breeding 25:259-272. https://doi.org/10.1007/s11032-009-9330-7

Gutiérrez N, Palomino C, Satovic Z, Ruiz-Rodríguez MD, Vitale S, Gutiérrez M, Rubiales D, Kharrat M, Amri M, Emeran A, Cubero JI, Atienza S, Torres AM, Avila CM (2013) QTLs for Orobanche spp. resistance in faba bean: identification and validation across different environments. Mol Breeding 32:909-922. https://doi.org/ 10.1007/s11032-013-9920-2

Joel DM, Hershenhorn Y, Eizenberg H, Aly R, Ejeta G, Rich PJ, Ransom JK, Sauerborn J, Rubiales D (2007) Biology and management of weedy root parasites. In: Janick J (ed) Horticultural reviews, vol 33. Wiley, NewYork, pp 267-350

Maalouf F, Khalil S, Ahmed S, Akintunde AN, Kharrat M, El Shama'a K, Hajjar S, Malhotra RS (2011) Yield stability of faba bean lines under diverse broomrape prone production environments. Field Crops Res 124:288-294. https://doi.org/10.1016/j.fcr.2011.06.005

McIntosh MS (1983) Analysis of combined experiments. Agron J 75:153155. https://doi.org/10.2134/agronj1983.00021962007500010041x

Pérez-de-Luque A, Flores F, Rubiales D (2016) Differences in crenate broomrape parasitism dynamics on three legume crops using a thermal time model. Front Plant Sci 7:1910. https://doi.org/10.3389/ fpls.2016.01910

Román B, Satovic Z, Rubiales D, Torres AM, Cubero JI, Katzir N, Joel DM (2002) Variation among and within populations of the parasitic weed Orobanche crenata from Spain and Israel revealed by inter simple sequence repeat markers. Phytopathology 92:1262-1266. https://doi.org/10.1094/PHYTO.2002.92.12.1262

Rubiales D, Ávila CM, Sillero JS, Hybl M, Narits L, Sass O, Flores F (2012) Identification and multi-environment validation of resistance to Ascochyta fabae in faba bean (Vicia faba). Field Crops Res 126: 165-170. https://doi.org/10.1016/j.fcr.2011.10.012
Rubiales D, Fernández-Aparicio M, Pérez-de-Luque A, Prats E, Castillejo MA, Sillero J, Rispail N, Fondevilla S (2009a) Breeding approaches for crenata broomrape (Orobanche crenata Forsk.) management in pea (Pisum sativum L.) Pest Manag Sci 65:553-559. https://doi.org/10.1002/ps.1740

Rubiales D, Fernández-Aparicio M, Wegmann K, Joel D (2009b) Revisiting strategies for reducing the seedbank of Orobanche and Phelipanche spp. Weed Res 49:23-33. https://doi.org/10.1111/j. 1365-3180.2009.00742.x

Rubiales D, Flores F, Emeran AS, Kharrat M, Amri M, Rojas-Molina MM, Sillero JC (2014) Identification and multi-environment validation of resistance against broomrapes (Orobanche crenata and O. foetida) in faba bean (Vicia faba). Field Crops Res 166:58-65. https://doi.org/10.1016/j.fcr.2014.06.010

Rubiales D, Moreno MT, Sillero JC (2005) Search for resistance to crenate broomrape (Orobanche crenata) in pea germplasm. Genet Resour Crop Evol 52:853-861. https://doi.org/10.1007/s10722003-6116-3

Rubiales D, Pérez-de-Luque A, Cubero JI, Sillero JC (2003) Crenate broomrape (Orobanche crenata) infection in field pea cultivars. Crop Prot 22:865-872. https://doi.org/10.1016/S0261-2194(03) 00070-X

Sánchez-Martín J, Rubiales D, Flores F, Emeran AA, Shtaya MJY, Sillero JC, Allagui MB, Prats E (2014) Adaptation of oat (Avena sativa) cultivars to autumn sowings in Mediterranean environments. Field Crops Res 156:111-122. https://doi.org/10.1016/j.fcr.2013.10.018

Villegas-Fernández AM, Sillero JC, Emeran AA, Flores F, Rubiales D (2011) Multiple-disease resistance in Vicia faba: multi-environment field testing for identification of combined resistance to rust and chocolate spot. Field Crops Res 124:59-65. https://doi.org/10. 1016/j.fcr.2011.06.004

Yan WK (2001) GGEbiplot. A windows application for graphical analysis of multienvironment trial data and other types of two-way data. Agron J 93:1111-1118. https://doi.org/10.2134/agronj2001. 9351111x

Yan WK (2002) Singular value partitioning for biplot analysis of multienvironment trial data. Agron Sustain Devel 94:990-996. https:// doi.org/10.2134/agronj2002.0990

Yan WK, Holland JB (2010) A heritability-adjusted GGE biplot for test environment evaluation. Euphytica 171:355-369. https://doi.org/10. 1007/s10681-009-0030-5

Yan WK, Hunt LA, Sheng QL, Szlavnics Z (2000) Cultivar evaluation and mega-environment investigation based on the GGE biplot. Crop Sci 40:597-605. https://doi.org/10.2135/cropsci2000.403597x

Yan W, Kang MS, Ma B-L, Woods S, Cornelius PL (2007) GGE biplot vs. AMMI analysis of genotype-by-environment data. Crop Sci 47: 643-653. https://doi.org/10.2135/cropsci2006.06.0374

Yang RC, Crossa J, Cornelius PL, Burgueño J (2009) Biplot analysis of genotype $\times$ environment interaction: proceed with caution. Crop Sci 49:1564-1576. https://doi.org/10.2135/cropsci2008.11.0665

Yang RC, Yeh FC, Yanchuk AD (1996) A comparison of isozyme and quantitative genetic variation in Pinus contorta spp. latifolia by FST. Genetics 142(3):1045-1052 